\title{
Role of PET-CT (Positron Emission Tomography-Computed Tomography) in Cancer Evaluation and Treatment
}

\author{
Balireddy Vasundhara ${ }^{1 *}$, Pottumuthu Hemalatha',2, Pakalapati Satya Sarath Kumar Raju1 \\ ${ }^{1}$ Department of Physics, GITAM Institute of Science, GITAM University, Visakhapatnam, India \\ ${ }^{2}$ Department of Nuclear Medicine \& PETCT, Omega Hospitals, Hyderabad, India \\ Email: *vbalired@gitam.edu
}

How to cite this paper: Vasundhara, B., Hemalatha, P. and Kumar Raju, P.S.S. (2022) Role of PET-CT (Positron Emission Tomography-Computed Tomography) in Cancer Evaluation and Treatment. World Journal of Nuclear Science and Technology, 12, 11-20.

https://doi.org/10.4236/winst.2022.121002

Received: September 14, 2021

Accepted: January 8, 2022

Published: January 11, 2022

Copyright $\odot 2022$ by author(s) and Scientific Research Publishing Inc. This work is licensed under the Creative Commons Attribution International License (CC BY 4.0).

http://creativecommons.org/licenses/by/4.0/

\section{(c) (i) Open Access}

\begin{abstract}
Context: Positron emission tomography is a nuclear medicine imaging that deals with physiological function using radioisotopes. With the most PET (Positron Emission Tomography) scanners in integration with the CT scanners of late, this technology has registered phenomenal growth. The small amount of radioactive material is called Radiotracers. Objective: Like ${ }^{18} \mathrm{~F}$ Fluro-deoxy-2-glucose has widely used. In this article, the author introduced clinical applications of PET out of 25 patients who studied hypermetabolic lesions in lymph nodes. Methods: PET imaging is coincidence imaging which is different from the other imaging technique PET image formed from multiple rings of detector crystals. Each decay positron travel in tissue annihilation reaction is going on. FDG is the most commonly used radiotracer to detect and stage various types of malignancies. Result: The field of PET/CT imaging cares for many oncology patients. PET improved localization of malignant lesions. It improved staging biopsy and therapy. Conclusion: Finally, studies to data showed $4 \%$ to $10 \%$ improvement in the overall accuracy of staging/restaging in lesions. If we use Monte Carlo simulation, OLINDA/EXM software may improve further with widely used.
\end{abstract}

\section{Keywords}

Positron Emission Tomography, Radio Isotopes, Lymphoma, Neo-Plasmas

\section{Introduction}

Positron Emission Tomography (PET) permits analytic imaging of metabolic capacity utilizing radioisotopes. This innovation has experienced development 
and advancement lately, with most PET scanners currently incorporated with CT scanners. PET \& CT were at first used as an examination apparatus in heart and neurological applications. At present, just masters and specialist doctors may allude to patients for PET sweep. A marked progression has been the equipment combination of CT scanners with PET scanners. Radiotracers made from Positron Emitting Isotopes can be utilized to picture an assortment of biological procedures in the body using a PET scanner [1].

Radiotracers manufactured from positron emanating isotopes can be utilized to picture the accessibility of natural procedures in the body using PET scanners. A positron is a decidedly charged electron radiated from the core of some low sub-atomic weight radioactive isotopes. These incorporate Carbon (C11), Nitrogen (N13), Oxygen (O18) and Fluorine (F18), which are building squares of the body. These isotopes have short lives (extending from $0-110$ minutes for F18) and must be fabricated close by cyclotron. A PET scanner doesn't legitimately picture positrons. When a positron is produced from the core, it ventures a short separation (a few millimeters in a delicate tissue), at that point demolishes with an adversely charged electron. The mass of two particles is changed into vitality as two gamma beams that proliferate at $180^{\circ}$ to one another.

Incidental gamma beam matches that movement out of the body are recognized by a ring of indicators around the Patient. The wording utilized in the way to deal with limiting CT radiation portion has limiting CT radiation has significant clinical ramifications. Portion decrease is a fundamental matter of changing CT portion parameters. On the off chance that the administrator decreases the $\mathrm{mA}$ setting, the radiation portion to the Patient is correspondingly diminished. The creators saw that CT and PET picture quality utilizing the most reduced portion strategy accessible. Since picture quality develops the portion, CT portion streamlining is principally an issue of picture quality instead of radiation portion. The second reasoning is Positron Emission Tomography (PET). The PET depends on recognizing the two $511 \mathrm{keV}$ destruction radiations that initially from $\beta^{+}$transmitting sources.

Example: The Patient containing $\beta^{+}$radiating radioactivity positrons end-obliterated in body tissue and produced two $5611 \mathrm{keV}$ destruction photons discharged in inverse $\left(180^{\circ}\right)$ course. The two photons are identified in an electronic time interim called the "Fortuitous event Time" window. Change $511 \mathrm{keV}$ photons to light photons in the finder, develop a heartbeat by the PM cylinder, and heartbeat stature examination pursue a similar rule as Gamma Camera. Information gathered over $360^{\circ}$ at the same time around the body pivot of the Patient is utilized to re-build the picture of movement, dissemination in the cut of intrigue. In PET electronic collimation system is utilized.

\section{Methods}

PET is a non-invasive, diagnostic imaging strategy for estimating the metabolic action of cells in the human body. Both FDG-positron emanation tomography 
and PC tomography assessed malignancy understanding. PET depends on identifying the two $511 \mathrm{keV}$ destruction radiation that begin from the $\beta^{+}$discharging source. All patients experienced routine assessment, including history and physical evaluation, chest radiography, electro-cardiograph, barium swallow and CT of the chest and upper abdomen.

Computer Tomography: All patients experienced complexity upgraded CT of the chest and upper mid-region. Printed version pictures were accessible and of admirable quality. The rest of the patients had CT at this organization with a Siemens soma tom in addition to S-Scanner. After the organization oral and intravenous differentiation operators, $10-\mathrm{mm}$ bordering pictures were gotten from the neck to beneath the degree of the liver Recorded, degree fundamentals growth, the thickness of the oesophageal divider, cancer intrusion of adjacent design and proximity of injuries suggestive of meta-static to isolate.

Clinical applications of PET in Oncology:

1) Diagnosis;

2) Biopsy guidance;

3) Staging;

4) Restaging;

5) Radiation Therapy Planning [2] [3].

Diagnosis and Staging research:

On the off chance that the Patient has Symptoms or a screening test result that recommends malignancy, your specialist must see if it is because of disease or some other reason. Contingent upon the indications patient may experience tests [4]. Malignant growth treatment abridges for adult and youth disease lab tests, imaging tests, and biopsy after the analysis of malignancy.

\section{Lab tests:}

Some lab tests include testing blood or tissue tests for lemur markers. Tumor markers are substances delivered by malignant growth cells or by different cells of the body in light of disease.

\section{Imaging tests:}

Imaging tests portray zones inside your body that help the specialist see whether a tumor is available. CT examine, MRI, Nuclear Scan, Bone Scan, PET sweep.

A CT check utilizes an X-beam machine connected to a PC to take aeries of the image of your organs from various edges. These photos are being used to make nitty-gritty 3-D imides of within your body.

\section{Restaging:}

It is a process used to determine the amount of spread of cancer in the body if it comes back or gets worse after treatment. Restaging may also be done to find out how cancer responds to treatment. If restaging is done and a new stage is assigned, it will mark the new location in front of it to show that it's different from the original set. Usually, the initial stage stays the same, even if cancer comes back or gets worse. The same tests done to diagnose the cancer are usually done again. Restaging helps doctors plan the best treatment for cancer that has come 
back or gotten worse [5] [6] [7].

A procedure used to elicit the spread of malignancy in the body, perchance that it returns or deteriorates after treatment. Restaging may likewise be done to infer how the malignant growth reacted to treatment. On the off chance that restaging is done and another stage is allotted, the new stage will be set apart with an " $r$ " before it to show that it's not the same as the first stage. Generally, the first stage remains the equivalent, regardless of whether the malignant growth returns or deteriorates [8]. Similar tests that did to analyze the disease are typically done once more. Restaging assists specialists with arranging the best treatment for the disease that has returned or deteriorated [9].

\section{Radiation Therapy Planning:}

Radiation treatment is a sort of malignancy treatment that utilizes light emissions vitality to execute disease cells. Radiation therapy frequently utilizes $\mathrm{X}$-beams; however, protons or different kinds of energy additionally can be utilized.

Radiation treatment damages cells by crushing the hereditary material that controls how cells develop and separate. While both solid and destructive cells are harmed by radiation treatment, the objective of radiation treatment is to pulverize as hardly many ordinary, sound cells as possible. Normal cells can regularly fix a significant part of the harm brought about by radiation.

Formula 1: ${ }^{18} \mathrm{~F}-\mathrm{FDG}=2$-deoxy- $2-{ }^{18} \mathrm{~F}$-Fluor-D-Glucose

The most versatile clinical pet radiopharmaceutical is ${ }^{18} \mathrm{~F}-\mathrm{FDG}$ [10] a glucose analog. 18F-FDG is accumulated in high consternation in metabolically active tumors and the brain and the myocardium as shown below.

Formula 2: ${ }^{18} \mathrm{~F}_{9} \rightarrow{ }_{8} \mathrm{O}^{18}+\beta^{+}+\eta$;

Formula 3: ${ }^{68} \mathrm{Ga}_{31} \rightarrow{ }^{68} \mathrm{Zn}_{30}+\beta^{+}+\eta$;

Formula 4: ${ }^{13} \mathrm{~N}_{7} \rightarrow{ }^{13} \mathrm{C}_{6}+\beta^{+}+\eta$;

Formula 5: $\mathrm{T}_{1 / 2}=109.7 \mathrm{~min}=110 \mathrm{~min}$;

Formula 6: $\mathrm{E}_{\max }=1.6456 \mathrm{meV}$ Molecular formula $\mathrm{C}_{6} \mathrm{H}_{11} \mathrm{~F}_{8} \mathrm{O}_{5}$;

Formula 7: Weight 181.1 atom $/ \mathrm{mole}=181.1 \mathrm{~g} / \mathrm{mole}$ [10]

0.15 mCurie per Kg (adults)

0.1 mCurie per $\mathrm{Kg}$ (children)

$0.1 \mathrm{mCurie}$ per $\mathrm{Kg}$ (adults)

0.1 mCurie per $\mathrm{Kg}$ (Children)

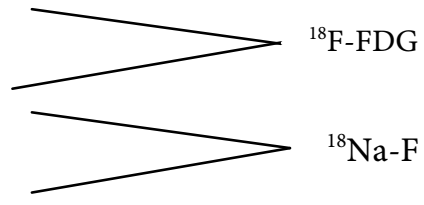

370 - $740 \mathrm{MBq}$ for adults Exposure dose from PET: $7.4 \mathrm{mSv}$ Effective dose from CT portion in perfect scan: $5-8 \mathrm{mSv}$. Two photons are distinguished in an electronic time interim called fortuitous event time window transformation of $511 \mathrm{keV}$ photons to light photons in the finder, development of a heartbeat by the PM Tube, and heartbeat tallness investigation pursues a similar standard as a gamma camera [11] [12]. Positron Emission Tomography is a practical demonstrative picture method. The capacity of PET to contemplate different organic procedures opens up new potential outcomes for both research and everyday clinical use. Consolidation of CT to PET improves recognition productivity and results in better localization of sores. 
F-18 fluoro-2-deoxy-glucose (FDG), simple glucose, altered sugar generally, utilized radiotracer in PET imaging. The F-18 FDG take-up is expanded many overlays in dangerous tumors. The primary goals of oncology imaging are sore discovery, injury characterization; assessment of the degree of the tumor, organizing PET gives additional data about functional conditions of the infection. Atomic prescription systems can be tedious. It can take a few hours to days for the radiotracer to aggregate in the body. Some portions of intrigue and imaging may take up to a few hours to perform [13] [14] [15] [16].

\section{Result}

In the PET/CT imaging field, the author studied 25 patients' data of hypermetabolic Lesions in lymph nodes in this article. Pre-treatment of Hyper metabolic Lesions is in the left side of the neck. In post-treatment compared with pre-review study, there is a significant reduction in the metabolic activity to treatment. And another image author observed in pre-treatment of hypermetabolic Lesions in the left side breast and multiple metastatic nodes in the liver. In post-treatment, no definite abnormal hype-metabolism is either in the breast or in the liver.

\section{Conclusion}

Future use of PET will probably originate from tracers other than FDG nononcology applications are likewise rising too, especially in the field of dementia, development issue and discovery of the disease. Notwithstanding the utilization of PET and SPECT Radio-nuclides for diagnostic imaging studies. Radionuclides used in nuclear medicine are ephemeral one PET-product, FDG in cardiology. The early use of cyclotron in the radiopharmaceutical field utilized brief PET Radio-nuclides, such as Fluorine-18, Carbon-11, Nitrogen-13, and Oxygen-15. Nuclear medicine is more affordable and may yield more exact data than an experimental medical procedure. The advantages of a combined PET/CT scanner are: it provides more significant details with more precision as both scans are performed at a time with no need for the Patient to change positions and better comfort for the Patient undergoing two examinations (CT and PET) in a single sitting, avoiding two different times. If we use Monte carol stimulation, OLINDA/EXM software may improve further with widely used.

\section{Conflicts of Interest}

The authors declare no conflicts of interest regarding the publication of this paper.

\section{References}

[1] Vaquero, J.J. and Kinahan, P. (2015) Positron Emission Tomography: Current Challenges and Opportunities for Technological Advances in Clinical and Preclinical Imaging Systems. Annual Review of Biomedical Engineering, 17, 385-414. https://doi.org/10.1146/annurev-bioeng-071114-040723 
[2] Anand, S.S., Singh, H. and Dash, A.K. (2009) Clinical Applications of PET and PET-CT. Medical Journal Armed Forces India, 65, 353-358. https://doi.org/10.1016/S0377-1237(09)80099-3

[3] Blake, M.A., Slattery, J.M., Kalra, M.K., Halpern, E.F., Fischmann, A.J., Mueller, P.R. and Boland, G.W. (2006) Adrenal Lesions: Characterization with Fused PET/CT Image in Patients with Proved or Suspected Malignancy-Initial Experience. Radiology, 238, 970-977. https://doi.org/10.1148/radiol.2383042164

[4] Schelling, M., Avril, N., Naukri, J., Kuhn, W., Romer, W., Sattler, D., Werner, M., Dose, J., Janacek, F., Grief, H. and Schweiger, M. (2000) Positron Emission Tomography Using $\left[{ }^{18} \mathrm{~F}\right]$ Fluorodeoxyglucose for Monitoring Primary Chemotherapy in Breast Cancer. Journal of Clinical Oncology, 18, 1689-1695.

[5] Jerusalem, G., Beguine, Y., Fossette, M., Najjar, F., Rigor, P. and Fillet, G. (1999) Whole-Body Positron Emission Tomography Using ${ }^{18}$ F-Fluorodeoxyglucose for Post-Treatment Evaluation in Hodgkin's Disease and Non-Hodgkin's Lymphomas Higher Diagnostic and Prognostic Value than Classical Computed Tomography Scan Imaging. Blood, 94, 429-433.

[6] Weinrich, M., Re, D., Scheid Hauer, K., Anson, S., Diolein, M., Bischoff, S., Bohlen, H., Wolf, J., Schicchi, H., Diehl, V. and Tisch, H. (2001) Thoracic Positron Emission Tomography Using 18F-Fluorodeoxyglucose for the Evaluation of Residual Mediastinal Hodgkin Disease. Blood, 98, 2930-2934.

[7] Rousseau, C., Devillers, A., et al. (2006) Monitoring of Early Response to Neoadjuvant Chemotherapy in Stage II and III Breast Cancer by $\left[{ }^{18} \mathrm{~F}\right]$ Fluorodeoxyglucose Positron Emission Tomography. Journal of Clinical Oncology, 24, 5366-5372.

[8] Avril, N., Sassan, S., Staffeldt, B., et al. (2005) Prediction of Response to Neoadjuvant Chemotherapy by Sequential F-18-Fluorodeoxyglucose Positron Emission Tomography in Patients with Advanced-Stage Ovarian Cancer. Journal of Clinical Oncology, 23, 7445-7458.

[9] Boring, C.C., Squires, T.S. and Tong, T. (1992) Cancer Statistics, 1992. CA: A Cancer Journal for Clinicians, 42, 19-38. https://doi.org/10.3322/canjclin.42.1.19

[10] Newiger, H. (1993) Die Positronen-Emissions-Tomographie (PET)—Eine neue, diagnostische Methode. Physikalische und technische Voraussetzungen [Positron-Emission Tomography (PET) - A New Diagnostic Method. Physical and Technical Requirements]. Aktuelle Radiologie, 3, 140-143.

[11] Rohrer, E.M., Turkington, T.G. and Coleman, R.E. (2004) Clinical Applications of PET in Oncology. Radiology, 231, 305-332. https://doi.org/10.1148/radiol.2312021185

[12] Libellee, S., Domain, C., Bonneau, G., Aspirin, A., Caillou, B., Lombroso, J., Segal, R., Boudin, E. and Schlumberger, M. (2006) Diagnostic and Prognostic Value of 18-Fluorodeoxyglucose Positron Emission Access Tomography in Adrenocortical Carcinoma: A Prospective Comparison with Computed Tomography. Journal of Clinical Endocrinology and Metabolism, 91, 920-925.

[13] Stanley, K.E. (1980) Prognostic Factors for Survival in Patients with Inoperable Lung Cancer. Journal of the National Cancer Institute, 65, 25-32.

[14] Gail, M.H., Eagan, R.T., Feld, R., et al. (1984) Prognostic Factors in Patients with Resected Stage I Non-Small Cell Lung Cancer. A Report from the Lung Cancer Study Group. Cancer, 54, 1802-1813.

https://doi.org/10.1002/1097-0142(19841101)54:9\%3C1802::AID-CNCR2820540908 \%3E3.0.CO;2-4

[15] Geddes, D.M. (1979) The Natural History of Lung Cancer: A Review Based on Rates 
of Tumor Growth. British Journal of Diseases of the Chest, 73, 1-17. https://doi.org/10.1016/0007-0971(79)90002-0

[16] Duallings, F.G., Lowe, V.J., Patz, E.F., Vaughn, A.L., Coleman, R.E. and Wolfe, W.G. (1995) Lung Tumor Growth Correlates with Glucose Metabolism Measured by Fluoride-18-Fluorodeoxyglucose Positron Emission Tomography. The Annals of Thoracic Surgery, 60, 1348-1352. https://doi.org/10.1016/0003-4975(95)00754-9 


\title{
List of Abbreviations
}

\author{
PET-Positron Emission Tomography \\ CT-Computed Tomography \\ FDG-Fluro-deoxy-2-glucose \\ MRI-Magnetic Resonance Image
}

\section{Appendix}

Table A1. Positron emission tomography data pertaining to the patient treated.

\begin{tabular}{ccccl}
\hline S1. No. & Patient ID & Fig No & Diagnosis & \multicolumn{1}{c}{ Findings } \\
\hline 1 & UMRG-8610 & Figure A1(a) & $\begin{array}{c}\text { NON-HODGKINSON } \\
\text { LYMPHOMA }\end{array}$ & $\begin{array}{l}\text { 1) Hyper metabolic Lesions in the left side of the neck } \\
\text { 2) Hyper metabolic in abdominal lymph nodes are lively } \\
\text { meta-static in nature }\end{array}$ \\
2. & UMRG-8610 & Figure A1(b) & $\begin{array}{c}\text { NON-HODGKINSON } \\
\text { LYMPHOMA }\end{array}$ & $\begin{array}{l}\text { 1) No definite abnormal hype-metabolism in the left side of } \\
\text { the neck and abdomen }\end{array}$ \\
& & $\begin{array}{l}\text { 2) Compared to the pre-review study, there is a significant } \\
\text { reduction in metabolic activity, suggesting favourable } \\
\text { response to treatment }\end{array}$ \\
3. & UMRG-6860 & Figure A2(a) & $\begin{array}{c}\text { CARCIONOMA OF LT } \\
\text { BREAST }\end{array}$ & $\begin{array}{l}\text { Hyper metabolic Lesions in the left side breast and multiple } \\
\text { metastatic nodes in liver }\end{array}$ \\
& & Figure A2(b) & $\begin{array}{c}\text { CARCIONOMA OF LT } \\
\text { BREAST }\end{array}$ & $\begin{array}{l}\text { No definite abnormal hype-metabolism in the either in } \\
\text { breast or in liver. }\end{array}$ \\
\hline
\end{tabular}

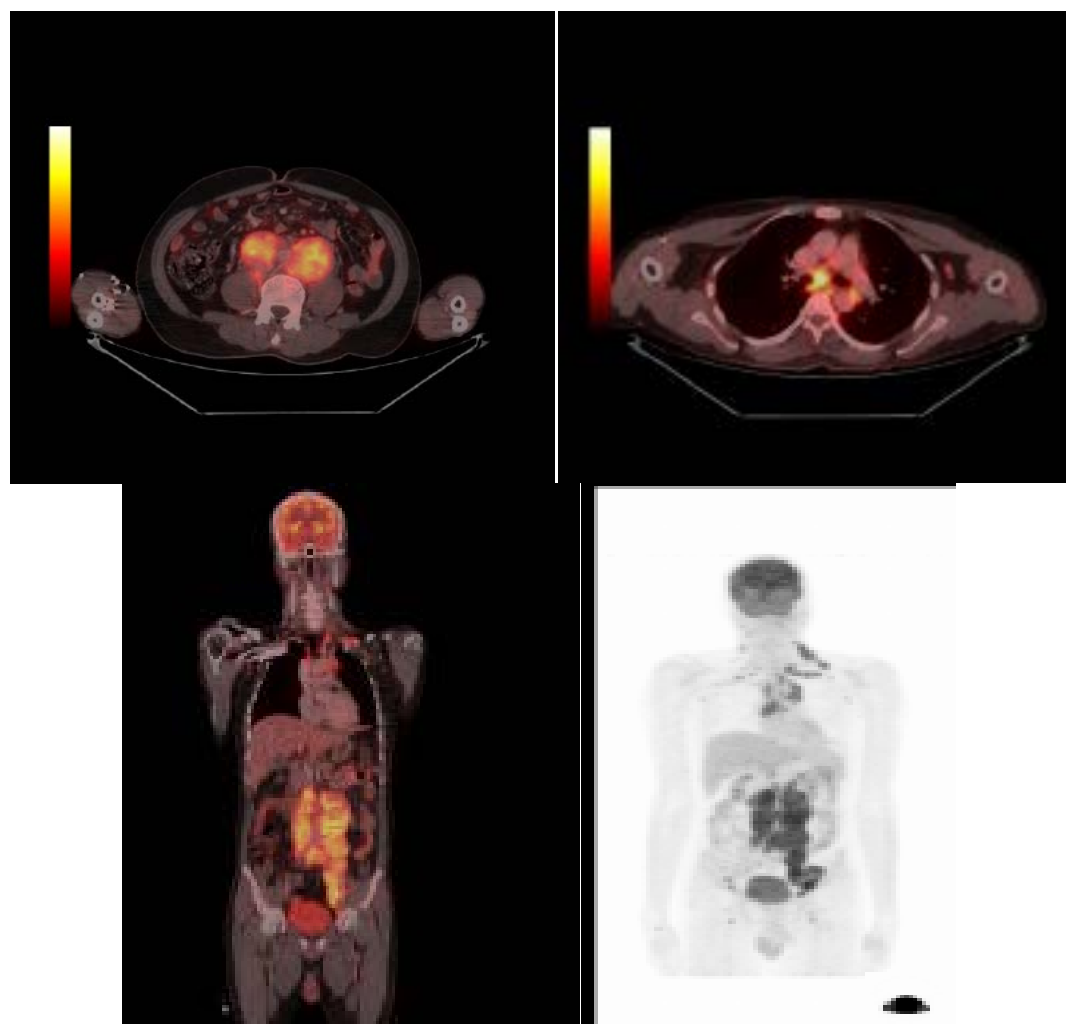

(a) 


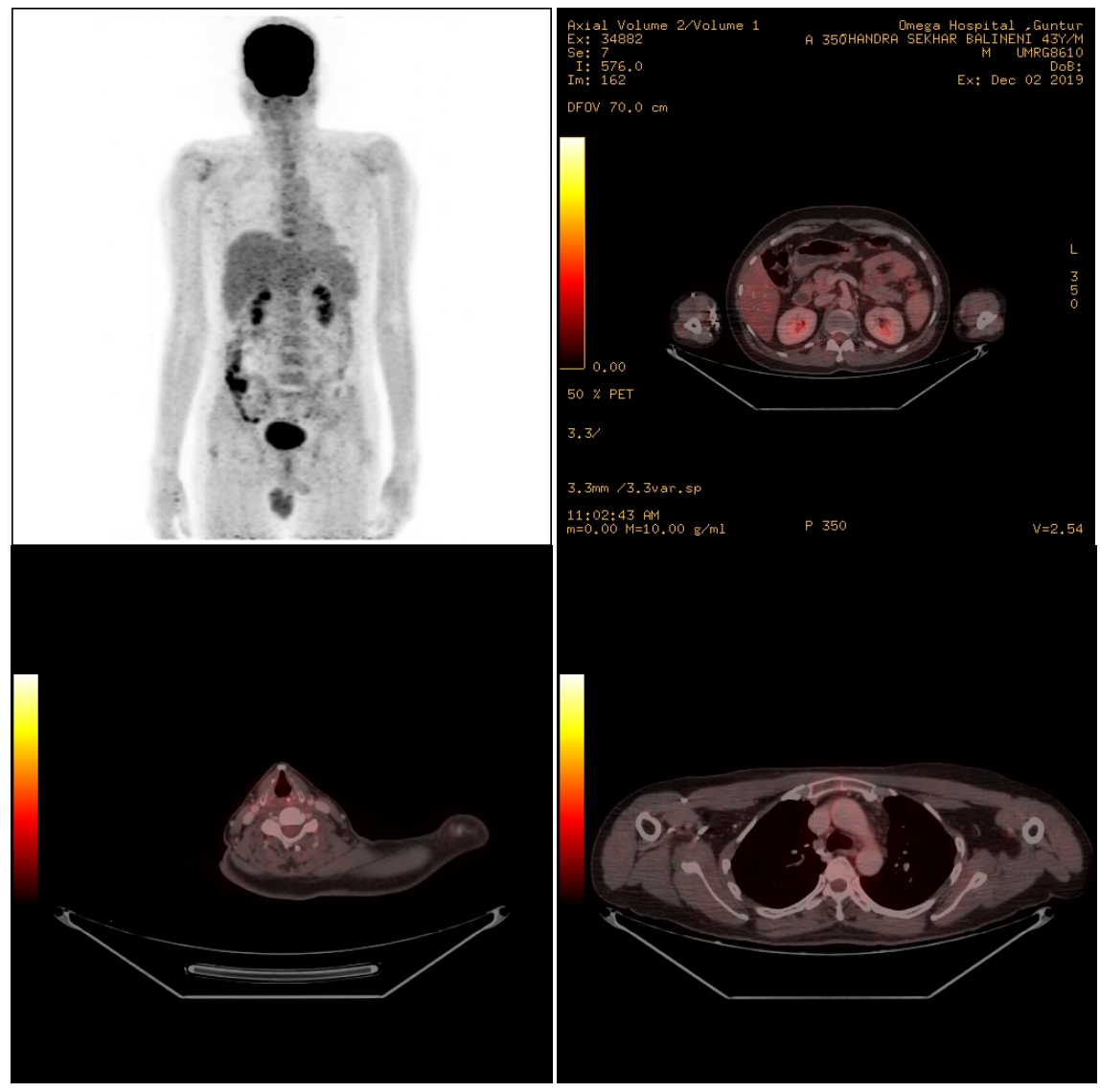

(b)

Figure A1. (a) Pre-treatment of UMRG 8610: 1) Hyper metabolic Lesions in the left side of the neck; 2) Hyper metabolic in abdominal lymph nodes are lively meta-static in nature. (b) Post-treatment of UMRG 8610: 1) No definite abnormal hype-metabolism in the left side of the neck and abdomen; 2) Compared to the pre-review study, there is a significant reduction in Metabolic activity, suggesting a favorable response to treatment. 


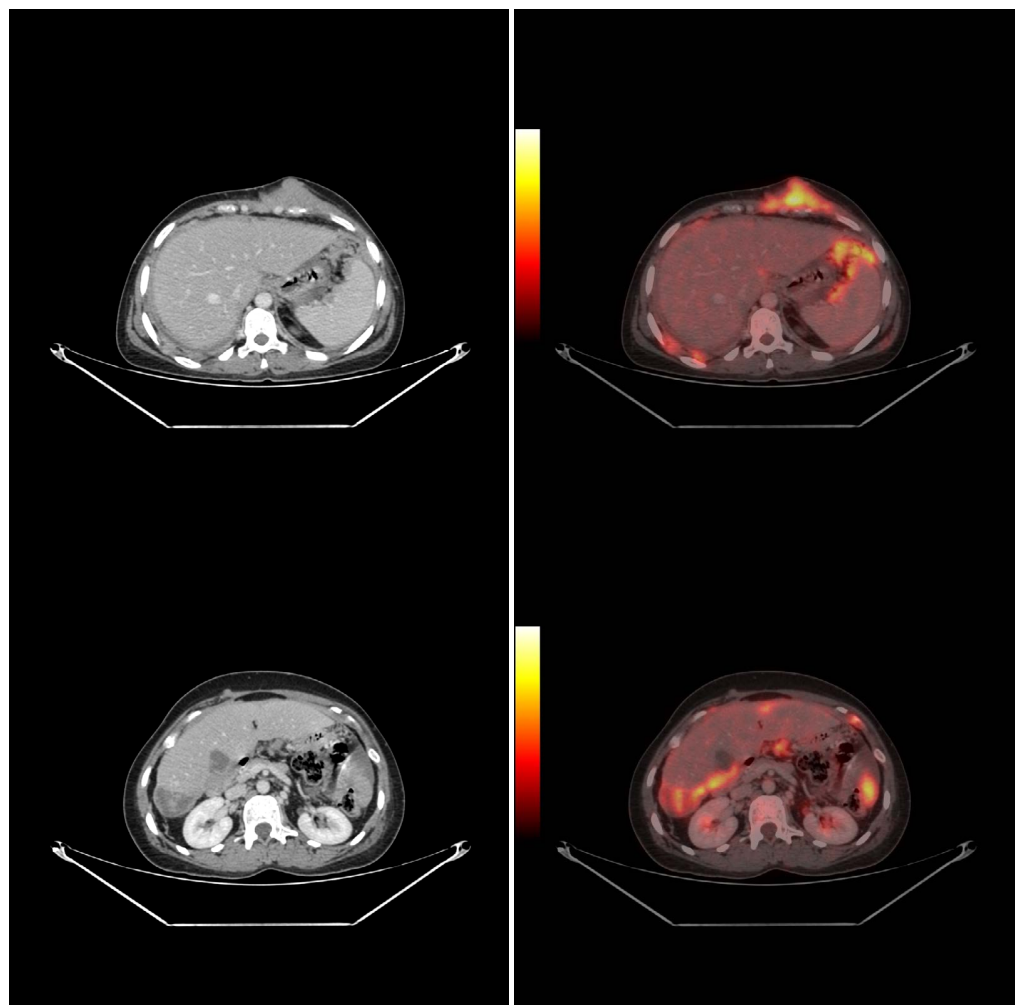

(a)

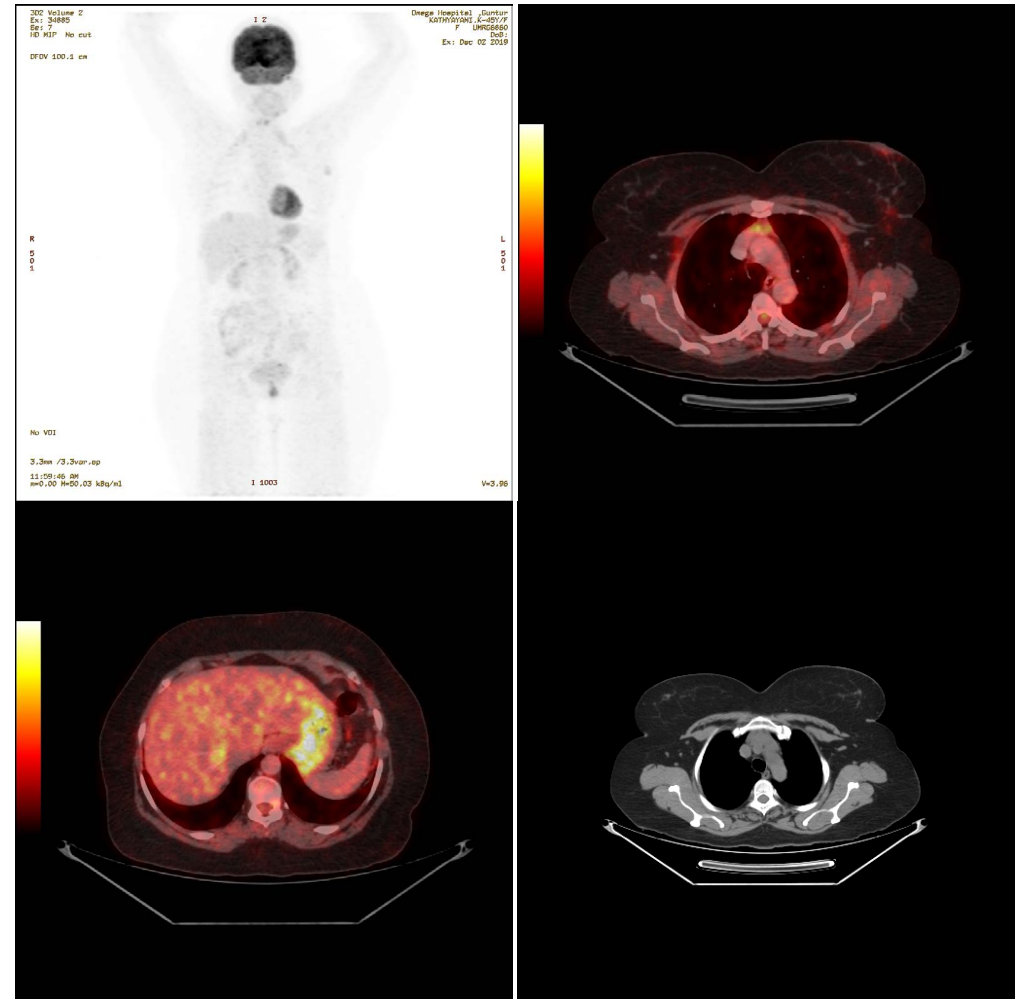

(b)

Figure A2. (a) Pre-treatment of UMRG 6860: Hyper metabolic Lesions in the left side breast and multiple metastatic nodes in liver. (b) Post-treatment of UMRG 6860: No definite abnormal hype-metabolism in either breast or the liver. 